\title{
Hydrogen Permeation of Heat Resisting Alloys*
}

\section{By Kanji MASUI ${ }^{* *}$ and Heitaro YOSHIDA**}

It is desirable that heat resisting alloys used for heat exchangers in a high temperature gas cooled reactor for multiple purposes have excellent high temperature mechanical properties and further that the hydrogen permeation is as low as possible.

Only few studies have been reported, however, on the hydrogen permeability of heat resisting alloys at high temperatures and the effect of metallurgical factors on the hydrogen permeation is not so much clear. $^{1-8)}$

In this note, an investigation has been made of hydrogen permeability in the temperature range from $800^{\circ}$ to $1000^{\circ} \mathrm{C}$ in one atmospheric pressure through four kinds of alloys: HK 40, Incoloy 800, Hastelloy $\mathrm{X}$, and Inconel 600 which were considered to be suitable for heat resisting alloys used for heat exchangers in a high temperature gas cooled reactor and compared these permeability values with those of pure iron and nickel. Further, the effect of addition of steam on hydrogen permeability of these alloys has also been examined.

\section{Materials}

Table 1 shows the chemical composition of alloys used. HK 40 was used as cast, and other three alloys were used after a solution treatment for one hour at $1050^{\circ} \mathrm{C}$ followed by water quenching. The specimen size is shown in Fig. 1.

Samples of pure iron and nickel were melted in a vacuum furnace, by using electrolytic iron (99.95\%) and nickel $(99.98 \%)$, then forged to the size of $30 \mathrm{~mm}$ square by hot rolling. The thickness of the specimen was about $2 \mathrm{~mm}$ except for special cases.

Specimen holders made from $18 \mathrm{Cr}-8 \mathrm{Ni}$ stainless steel (AISI 304) were welded to a specimen by electron beam at the both sides. The roughness of the specimen surface was less than $0.5 \mu \mathrm{m}$, and the specimen surface was rinsed in petroleum benzine and trichloroethylene to remove the anti-corrosion oil.

\section{Device}

The device for measuring hydrogen permeability,
Fig. 2, consisted of five systems: the refining, humidification, heating, measuring, and vacuum systems. Hydrogen permeated through a specimen was collected into the measuring tank which was kept at a vacuum, and the hydrogen permeability at normal temperature and pressure (N.T.P.) was calculated from the
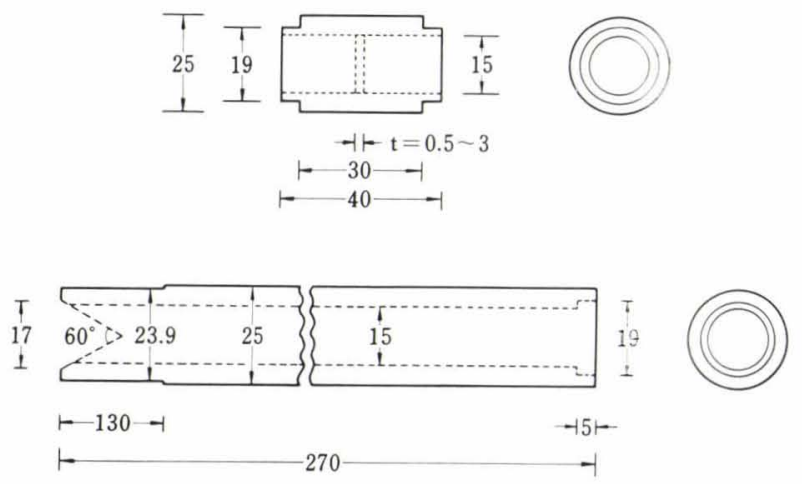

Fig. 1. Specimen and specimen holder
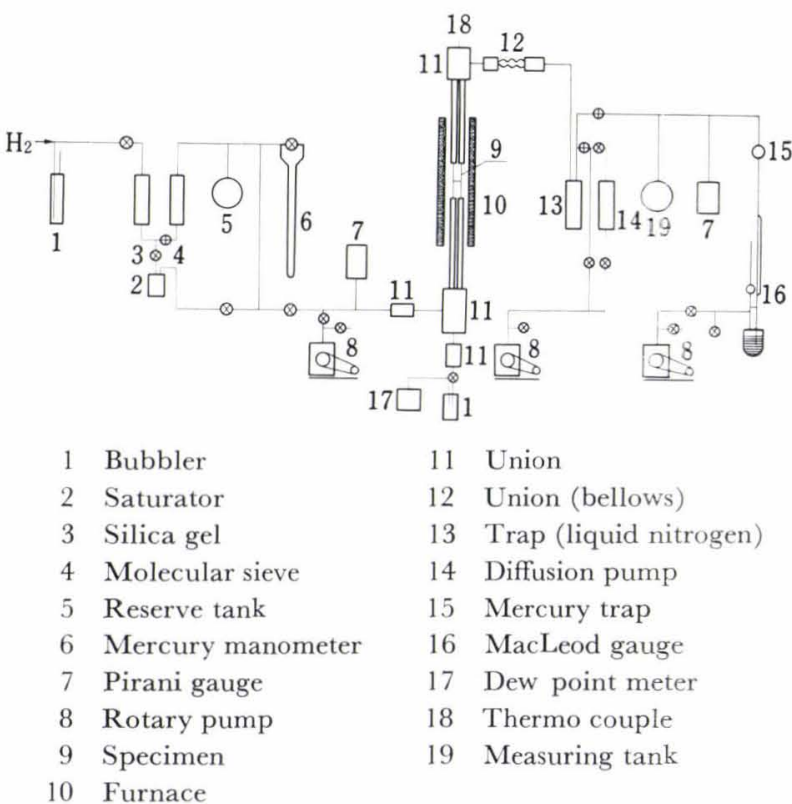

11 Union

12 Union (bellows)

13 Trap (liquid nitrogen)

14 Diffusion pump

15 Mercury trap

16 MacLeod gauge

17 Dew point meter

18 Thermo couple

19 Measuring tank

Fig. 2. Measuring device for hydrogen permeation

Table 1. Chemical composition of alloys (wt \%)

\begin{tabular}{|c|c|c|c|c|c|c|c|c|c|}
\hline Alloys & $\mathrm{Ni}$ & $\mathrm{Cr}$ & $\mathrm{Fe}$ & $\mathrm{Si}$ & $\mathrm{Mn}$ & $\mathrm{C}$ & \multicolumn{3}{|c|}{ Other elements } \\
\hline Hn 70 & 22.0 & 23.0 & Dal. & 0.01 & 0.53 & 0.40 & & & \\
\hline Incoloy 800 & 31.59 & 20.72 & bal. & 0.48 & 0.93 & 0.04 & $\mathrm{Ti}: 0.35$ & $\mathrm{Al}: 0.45$ & \\
\hline Hastelloy X & 47.97 & 21.22 & bal. & 0.50 & 0.60 & 0.09 & Mo: 8.82 & Co: 1.27 & $W: 0.59$ \\
\hline Inconel 600 & 73.25 & 15.91 & bal. & 0.41 & 0.34 & 0.05 & & & \\
\hline
\end{tabular}

* Received December 11, 1973.

** National Research Institute for Metals, Nakameguro, Meguro-ku, Tokyo 153. 
increase in pressure measured by a MacLeod gauge.

Impurity oxygen in hydrogen $(99.999 \%$ ) was removed by paladium black, then humidity was removed by silica gel and molecular sieve, further, small amounts of residual $\mathrm{H}_{2} \mathrm{O}, \mathrm{O}_{2}$ and $\mathrm{N}_{2}$ were gettered by Zr-sponge.

A specimen was degassed in a vacuum higher than $10^{-5} \mathrm{mmHg}$ at least for $5 \mathrm{hr}$ at $1000^{\circ} \mathrm{C}$, and then the hydrogen permeation was measured. The temperature was measured by an alumel-chromel thermocouple touched directly with the specimen.

\section{Hydrogen Permeation through Metals and Alloys by Using High Purity Hydrogen}

Figure 3 shows the relation between the hydrogen permeation and testing temperature. The logarithm of the hydrogen permeability is linearly proportional to the reciprocal of the absolute temperature. The unit of permeability is $\mathrm{cm}^{3}$ (N.T.P.) $\cdot \mathrm{mm} / \mathrm{hr} \cdot \mathrm{p}^{1 / 2} \cdot \mathrm{cm}^{2}$ which means the volume of hydrogen permeated at normal temperature and pressure per unit area $\left(\mathrm{cm}^{2}\right)$, thickness $(\mathrm{mm})$, root of pressure difference $\left(\mathrm{atm}^{1 / 2}\right)$, and time (hr).

The processes of hydrogen permeation through metals are as follows. ${ }^{1)}$

(a) Adsorption of molecular hydrogen on the metal surface and its decomposition into the atoms

(b) Solution of hydrogen into the metal

(c) Diffusion of hydrogen through the metal

(d) Migration of hydrogen to the other surface of the metal

(e) Combination of hydrogen atoms on the metal surface and desorption

The diffusion process of (c) becomes the rate-controlling step in the hydrogen permeation through metals at high temperature, if the surface is clean and the surface reaction is fast.

Hydrogen flux, $J$, is expressed for one dimentional flow by Fick's first law,

$$
J=-D d C / d X
$$

where, $D$ : diffusion coefficient of hydrogen

$d C / d X$ : concentration gradient along the $\mathrm{X}$-axis, which is normal to the surface of the membrane.

In the steady-state gas flow, $J$ is simplified as below,

$$
J=-D\left(C_{2}-C_{1}\right) / d
$$

where, $\quad d$ : membrane thickness

$C_{1}, C_{2}$ : hydrogen concentration at the inlet and outlet surfaces.

Between the hydrogen concentration $C$ and hydrogen solubility $S$, the next relationship is fulfilled by Sievert's law,

$$
C=S \sqrt{ } P
$$

where, $P$ : hydrogen pressure.

Then, $J=-D S\left(\sqrt{P_{2}}-\sqrt{P_{1}}\right) / d$ is obtained. When $P_{2}$ is maintained at nearly zero,

$$
J=D S \sqrt{ } P_{1} / d
$$

We adopt that the flux $J$ is the permeability at 1 atmosphere and $1 \mathrm{~mm}$ membrane thickness, consequently we express the permeability as follow,

$$
P=D \cdot S
$$

The hydrogen permeability through nickel at $700^{\circ} \mathrm{C}$, measured in this experiment was $1.4 \mathrm{~cm}^{3}$ (N.T. P.) $\cdot \mathrm{mm} / \mathrm{cm}^{2} \cdot \mathrm{hr} \cdot \mathrm{p}^{1 / 2}$. This value was nearly equal to $1.0 \mathrm{~cm}^{3}$ (N.T.P.) $\cdot \mathrm{mm} / \mathrm{cm}^{2} \cdot \mathrm{hr} \cdot \mathrm{p}^{1 / 2}$ calculated from Eq. (5), by adopting $0.58 \mathrm{~cm}^{3} / \mathrm{cm}^{310)}$ and $5 \times 10^{-5} \mathrm{~cm}^{2}$ $\sec ^{9)}$ respectively as the solubility $(S)$ and diffusion coefficient $(D)$ of hydrogen in nickel at $700^{\circ} \mathrm{C}$. The hydrogen permeability of iron at $1000^{\circ} \mathrm{C}$ measured in this experiment was $2.0 \mathrm{~cm}^{3}$ (N.T.P.) $\cdot \mathrm{mm} / \mathrm{cm}^{2}$. $\mathrm{hr} \cdot \mathrm{p}^{1 / 2}$. This value was nearly equal to $1.5 \mathrm{~cm}^{3}$ (N. T.P.) $\cdot \mathrm{mm} / \mathrm{cm}^{2} \cdot \mathrm{hr} \cdot \mathrm{p}^{1 / 2}$ calculated from Eq. (5) by adopting $0.44 \mathrm{~cm}^{3} / \mathrm{cm}^{311)}$ and $\left.0.96 \times 10^{-3} \mathrm{~cm}^{2} / \mathrm{sec}^{12}\right)$ respectively as the solubility $(S)$ and diffusion coefficient $(D)$ of hydrogen in iron at $1000^{\circ} \mathrm{C}$.

The relation of $P=D \cdot S$ is fairly fulfilled to the hydrogen permeation in a steady state in which the diffusion process is determinative.

Next, $D$ and $S$ are expressed as follows. ${ }^{3)}$

$$
\begin{gathered}
D=D_{0} \exp \left(-E_{D} / R T\right) \\
S=S_{0} \exp \left(-E_{S} / R T\right)
\end{gathered}
$$

Here, $E_{D}$ and $E_{s}$ mean the activation energies of diffusion and solution of hydrogen respectively.

Then,

$$
\begin{aligned}
P=D \cdot S & =D_{0} \cdot S_{0} \exp \left\{-\left(E_{D}+E_{S}\right) / R T\right\} \\
& =P_{0} \exp \left(-E_{P} / R T\right) \ldots \ldots \ldots \ldots \ldots \ldots
\end{aligned}
$$

As shown in Fig. 3, logarithm of hydrogen permeation is proportional to the reciprocal of the absolute temperature. This fact is reasonable according to Eq. (6).

The results obtained in this experiment are as follows.

(1) The hydrogen permeability of nickel was larger than that of iron $(r)$ in the temperature range from $800^{\circ}$ to $1000^{\circ} \mathrm{C}$.

(2) The hydrogen permeabilities of the four alloys shown in Table 1 were between that in pure

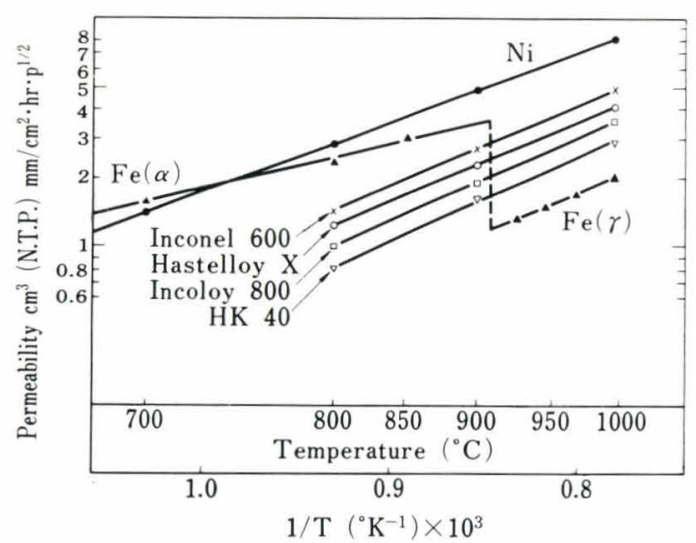

Fig. 3. Hydrogen permeability vs. temperature in pure metals and alloys 


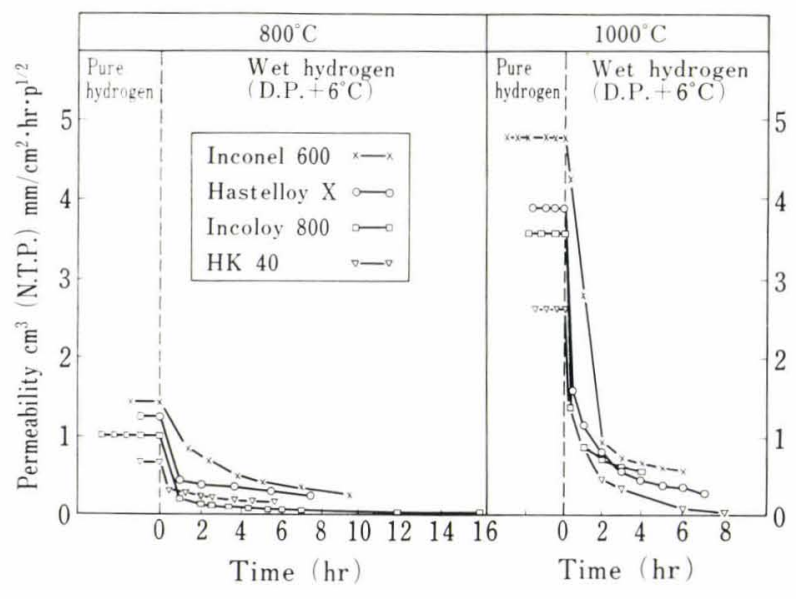

Fig. 4. Change in hydrogen permeability of alloys with elapsed time

nickel and that in iron. A close relation was observed between the hydrogen permeability and the iron and nickel contents in the four alloys. Namely, the more the nickel content in the alloy, the larger the hydrogen permeability became.

\section{Hydrogen Permeation through Alloys by Using Wet Hydrogen}

Figure 4 shows the change in hydrogen permeation of the four alloys at $800^{\circ}$ and $1000 \mathrm{C}^{\circ}$ vs. the elapsed time by using wet hydrogen having a dew point of $+6^{\circ} \mathrm{C}$. The hydrogen permeation scarcely changed by the test times in these alloys when very pure hydrogen was used. By addition of steam, a remarkable decrease in the hydrogen permeation is recognized in a short time.

The higher the temperature, the more remarkable the tendency of the decrease in hydrogen permeation.

By the use of X-ray diffraction, electron diffraction, and EPMA, examinations were made on the sub- stances formed on the surface of the specimen in which the hydrogen permeation decreased. It was found that substances formed on the surface were $\mathrm{Cr}_{2} \mathrm{O}_{3}$ and a spinel type oxide. The atmosphere of hydrogen having a dew point of $+6^{\circ} \mathrm{C}$ caused the selective oxidation of alloying elements such as $\mathrm{Cr}, \mathrm{Si}, \mathrm{Mn}$ etc. The decrease in hydrogen permeation can be explained to be due to an oxide film formed on the surface. Similar phenomena were reported by Huffine $e t a l .^{4)}$ and by Flint $^{5)}$ regarding an $\mathrm{Fe}-20 \mathrm{Cr}-5 \mathrm{Al}$ alloy and 347 stainless steel respectively. It is also reported ${ }^{13)}$ that the hydrogen diffusion coefficients of oxides are remarkably smaller than those of metals. The authors conclude that hydrogen permeation through heat resisting metals decreases by oxide films formed on the specimen surface.

The authors thank Mr. Hoshi who contributed to set up the device for measuring hydrogen permeation.

\section{REFERENCES}

1) J. K. Gorman and W. R. Nardella: Vacuum, 12 (1962), 19.

2) R. W. Webb: NASA-SR-10462.

3) W. M. Robertson: "Hydrogen in Metals" Jülich-Conference, Vol. 2, March, (1972), 449.

4) C. L. Huffine and J. M. Williams: Corrosion, 16 (1960), 430.

5) P. S. Flint: KAPL. Report, (1951), 659.

6) D. W. Rudd and J. B. Vetrano: NAA-SR-6109.

7) C. J. Engberg: NASA-SR-TDR-12425.

8) D. W. Rudd, D. W. Vose and J. B. Vetrano: NAA-SR4898.

9) M. L. Hill and E. W. Johnson: Acta Met., 3 (1955), 566.

10) S. Duchman: Scientific Foundations of Vacuum Technique, John Wiley and Sons Inc., New York, 1949.

11) L. Luckemeyer-Hasse and H. Schenck: Arch. Eisenhüttenw., 6 (1932), 209.

12) H. Schenck and H. Taxhut: Arch. Eisenhüttenw., 30 (1959), 661.

13) M. R. Piggott and A. C. Siarkowski: JISI, 210 (1972), 901. 